WATER DEVELOPMENT AND ENVIRONMENT

\author{
Asit K. Biswas
}

July 1978

Professional Papers are not official publications of the International Institute for Applied Systems Analysis, but are reproduced and distributed by the Institute as an aid to staff members in furthering their professional activities. Views or opinions expressed herein are those of the author and should not be interpreted as representing the view of either the Institute or the National Member Organizations supporting the Institute. 

Water Development and Environment

by

Asit K. Biswas

Keynote Lecture for International Conference on Water Pollution Conference for Developing Countries, sponsored by International Water Resources Association and International Association for Water Pollution Research, February 21-26, 1978, Bangkok, Thailand. 

INTRODUCTION

Water, according to the Greek philosopher, Pindar, of the fifth century B.C., is the best of all things. It could perhaps be an overstatement, but the fact remains that it is one of the basic compounds without which life in any form is not possible in this world. Man, animal and plants need water for survival. Water is essential for satisfaction of all basic human needs. Water is a basic ingredient for food production and further increase in the world's food production will be difficult without instituting better water control. Water provides energy in the form of hydroelectricity, and certain countries, like Sri Lanka, are nearly 100\% dependent on hydropower for their electricity generation. Even for thermal and nuclear power stations, substantial amounts of cooling water is necessary to dissipate heat. Industry cannot function without water, and water is invariably the focal point for many types of recreation.

ENVIRONMENT AND DEVELOPMENT

It is thus evident that water development is essential for economic development of developing countries. Hence, the fundamental question that should be asked is not whether there should be water developments, but rather how to meet the basic human needs and aspirations of all the world's people, without simultaneously destroying the resource base, that is, the environment, from which these needs must be met. This means that "environment" must be looked at in a broader context: it can no longer be viewed only in terms of environmental pollution--such as water, air and soil pollution--just as economic and social developments can no longer be adequately measured solely in terms of growth in gross national products.

In the early seventies, and during the United Nations Conference on the Human Environment, held in Stockholm in 1972, several countries erroneously viewed pursuit of environmental quality through adequate pollution control measures as an obstacle to economic development. Measures to preserve and enhance environmental quality were seen to be only the prerogative of the rich Western countries. While this type of thinking has greatly changed during the past six years, mainly due to the admirable work done by the United Nations Environment Program, the thinking has not been completely eliminated. For example, in 1977 Brazil argued strongly at the United Nations Water Conference, held at Mar del Plata, Argentina, that environmental protection measures are serious obstacles to development (Biswas, M.R., 1977). 
Fortunately, this type of thinking is not very prevalent at present.

There have been significant advances in recent years in our understanding of environment and development objectives, and generally it has now been accepted that these two objectives tend to converge. Environment is now being viewed as the stock of physical and social resources available at a given time for the satisfaction of human needs, and development as a process pursued by al1 societies with the aim of increasing human well-being (UNEP, 1976). In other words, the ultimate purpose of both environmental and development policies is the enhancement of the quality of life, beginning with the satisfaction of the basic human needs. This thinking is reflected in the formulation of new terminologies such as "alternative development", "new styles of development", or "alternative life styles", which suggest a more rational way of looking at the development process, one in which environmental considerations play a central role. A new kind of thinking on the environment-development interrelationship is necessary because development must be related not only to the opportunities offered by the available natural resource base, but al so to the constraints imposed by that base upon various human activities. It is simply not desirable to pursue development strategies that are not sustainable over a long-term basis due to serious environmetnal damages. In other words, development must proceed without destruction, and this principle must hold good for both developed and developing countries. Ilt is most important that the new forms of development in the developing world, in order to be self-sustaining, must be based on environmentally sound practices in relation to their natural resources base of soil, water, plant and animal life. These practices should be in harmony with the resource base, and should not contribute to their eventual destruction. Water development, like any other form of resource development, should fall under this overall guideline.

A11 resource development projects have social, economic and environmental consequences and water development is no exception. Whether such consequences are acceptable or not are often matters of great controversy, and depend very much on the individuals concerned, their personal interests, views, and biases. Hence, it is not exactly uncommon to find a situation where a new water development project is unacceptable to a certain segment of the society due to unwarranted social and environmental side-effects, while another segment may be lobbying hard for the same development for different reasons. To a certain extent, such conflicts can be explained by an analysis of the nature 
of the beneficiaries, which is seldom conducted for most projects. It is inevitable that any development project will benefit some citizens more than others, and frequently some citizens may have to bear additional costs, both tangible (i.e. heavier tax liabilities) and intangible (i.e. social and environmental costs). Resolution of such conflicts, difficult though they may be, arising within the framework of democratic pluralistic societies, through political processes, is however normal rather than the exception.

The social and environmental consequences of water development are many, and the resulting effects often extend much further than the planning area itself. The interaction of diverse forces are often so complex that ecologists and environmentalists are hard-pressed to predict overall effects with any degree of certainty (Biswas, 1973). For example, the present knowledge of ecosystems of man-made lakes leaves much to be desired, and unless planning precedes construction by five to ten years, several unpredictable and unforeseen situations could occur. At the current state-of-the-art, environmentalists often find it impossible to convince engineers, economoists and politicians that certain developments are unwise, or of the necessity to spend scarce resources on appropriate remedial measures because of lack of hard facts or solid scientific evidence. In addition, water development projects have been traditionally dominated by enigneers and economists, and consequently social and environmental considerations have often been sadly neglected during the planning process. In certain cases, social and environmental scientists have been brought in only after the damage has become apparent (Biswas and Durie, 1971). As a rule, it is more expensive to rectify damages once they have occurred: it is cheaper to take anticipatory remedial measures. Hence, even though much 1 ip-service is given to interdisciplinary teamwork, it is still an exception rather than the rule.

Since the social and environmental effects of water development are many, it can best be discussed by dividing the effects on three general subsystems-physical, biological and human.

\section{PHYSICAL SUBSYSTEM}

Water development projects invariably change river and ecosystem regimes, and thus the real question is not whether such developments will affect the environment, but how much change is acceptable to society as a whole, and what countermeasures should be taken to keep the adverse changes to a minimum, at a reasonable economic cost within that acceptable range. Qne of the 
largest dams in the world, the Aswan in Egypt, has received its share of criticisms for contributing to environmental disruptions. The scheme, completed in 1968, was built primarily for generating hydropower, but it has contributed to many social and environmental problems. A detailed analysis of the benefits and the costs of the Aswan Dam has yet to be made, but many of these effects can now be perceived and are summarized below.

First is the question of silt. Before the dam was constructed, large amounts of silt used to be either deposited in the Nile Valley or carried all the way to the delta and the sea. These sediments are now being trapped in the reservoir, Lake Nasser, created by the dam. Before the dam was built, suspended matter in the River Nile, passing the Aswan, ranged between 100 to 150 million tons per year. Observations made during the first few years after the completion of the dam indicate that the reservoir is losing about 60 million cubic meters of storage per year due to siltation. At this rate, the dead storage capacity of $30 \mathrm{~km}^{3}$ will be filled in about 500 years. As a result of the siltation in the reservoir, clear water is flowing downstream of the dam, causing erosion to the river bed and banks. One possibility now being considered is to construct a number of barrages to reduce the velocity and force of the clear water, and generate electricity at the same time.

Another effect of the siltation in the reservoir is erosion of the Nile Delta, some $1000 \mathrm{~km}$ away. Prior to the construction of the dam, the Delta used to be built up during the flood season, with the silt carried by the River to the Mediterranean. This situation in the Delta compensated for the erosion that resulted from the winter waves of the preceding year. Without enough siltation, erosion of the Delta has become a major problem and studies are now being carried out to find a suitable solution.

Loss of silt has further affected the productive capacity of the Nile Valley which used to get regular deposits of sediments every year. Currently studies are being undertaken to assess the actual nutritive value of the silt, and the trace elements present therein, so that this loss can be compensated by using chemical fertilizers.

Lack of sediments downstream of the dam has contributed to the significant reduction of planktons and organic carbons. It has, in turn, reduced the sardine, scrombroid and crustacean population of the area. Loss of sardine along the Eastern Mediterranean has created economic problems for the fishermen who used to depend on the catch for their livelihood. Furthermore, there was a thriving small-scale industry making bricks from the silt dredged from 
the canals. In the absence of such silts, many such industries have now resorted to using the topsoil near the canals to make bricks, thus contributing further to the loss of productive soil in the country. On the positive side, however, lack of silt has reduced the cost of dredging of channels.

Besides this situation, other environmental problems created by the Aswan Dam that could be included within the physical subsystem, are change of terrestrial system to aquatic system, hydrometeorological effects, and changes in soil and water quality. The High Dam created a vast reservoir, having a shoreline length of $9,250 \mathrm{~km}$, surface area of $6,216 \mathrm{~km}^{2}$ and volume of $156.9 \mathrm{~km}^{3}$ at 180 meters elevation. It changed $500 \mathrm{~km}$ of the River $\mathrm{Nile}$ from a riverine to lacustrine system. Though much of the land inundated was thinly populated, it contained areas rich in historical monuments, foremost of which was the Abu Simbel temple. Thus, the temples of Abu Simbel and Philae (near Aswan) had to be dismantled and moved to higher locations. The huge man-made reservoir also changed the micro-climate of the area. It was calculated that the raising of the water level by $20 \mathrm{~m}$, from $160 \mathrm{~m}$ to $180 \mathrm{~m}$, more than doubled the lake surface from $2,950 \mathrm{~km}^{2}$ to $6,118 \mathrm{~km}^{2}$, which increased the total annual evaporation from $6 \mathrm{~km}^{3}$ to $10 \mathrm{~km}^{3}$ (Hafez and Shenouda, 1977).

The construction of the High Dam and Canal system for irrigation has tended to increase the water table in many parts of Egypt. Such developments, and the tendency to over-irrigate, are contributing to an increase in the soil salinization problem, requiring expensive and extensive construction of drainage systems. With the disappearance of the annual Nile floods, the groundwater level has rather stabilized at a higher level. The salinity in the irrigation canals is increasing and some of the reclaimed lands are already facing a salinization problem.

The discussion of the above environmental effects of the Aswan High Dam is not meant to be a total condemnation of the structure, nor does it imply that it should never have been built. The benefits of the dam are many, and like evaluation of any other project, the benefits and costs should be evaluated and compared. It should be noted that the per capita cultivated land in Egypt has been reduced from 0.41 acres in 1930 to 0.18 acres in 1975 (Abl Atta, 1977). Without the Aswan Dam, the situation clearly would have been much worse. Furthermore, it has doubled the electric power availability of the country, provided flood protection, improved river navigation, created a vast potential for fishery in Lake Nasser--more than compensating the losses of sardine along the Mediterranean coast, and enhanced the potential for 
tourism in the Aswan Area. Thus, the real question is not whether the Aswan Dam should have been built, but rather what steps should have been taken to reduce the environmental impacts to a minimum.

There are cases where water development projects to increase irrigated agriculture have also contributed to problems which eventually reduced the total food production. Among such problems are deterioration of soil fertility and eventual loss of good arable land, due to progressive development of salinity or alkalinity. For example, at one time Pakistan alone was losing 24,280 hectares of fertile cropland every year, and currently nearly $10 \%$ of the total Peruvian agricultural area is affected by land degradation due to salinization. Among other major areas affected by salinization are the Helmud Valley in Afghanistan, the Punjab and Indus Valleys in the Indian subcontinent, Mexicali Valley in Northern Mexico and the Euphrates and Tigris basins in Syria and Iraq (Biswas and Biswas, 1975).

Finally, the possibility of inducing earthquakes by construction of large dams is another environmental problem that has not received adequate attention so far. The 1967 Konya Dam disaster in the Indian peninsula, which resulted in a heavy loss of lives and considerable property damage, was due to an earthquake whose epicentre coincided with the dam itself. Several recent studies indicate that the observed seismic activity can be attributed directly to the creation of dams and storage reservoirs. Some of the tremors thus caused can reach magnitudes of up to six on the Richter scale and thus cause considerable damage. In general, the seismic disturbances can be traced to the existence of inactive faults and it seems likely that the effect of the added forces contributed by the dam and reservoir liberate orogenic tensions of much greater strength. Studies at the Kariba Dam sites appear to confirm this theory. It also appears that the height of the water column is a more important parameter in inducing earthquakes than the total volume of the reservoir. The seismic activity tends to become more pronounced once the depth exceeds $100 \mathrm{~m}$ (Biswas and Biswas, 1976: Rothe, 1973).

BIOLOGICAL SUBSYSTEM

Water resources development can affect biological subsystems in many different ways, and the effects can be either beneficial or adverse. Since the quality of water is of prime importance to human health, the availability of potable water to much of mankind is literally a matter of 1 ife and death. The World Health Organization (WHO) carried out a survey in 1976 on the 
availability of potable water in developing countries to the end of 1975 . Based on the survey questionnaire that was returned by 67 developing countries, the following seems to be the current situation. In urban communities $57 \%$ of the population have house connections and another 18\% have access to standpipes, making a total of $75 \%$ (390 million people) that have access to potable water. The situation, as might be expected, is far worse for the rural sector, where only $20 \%$ (248 million) have reasonable access to safe water. If both rural and urban populations are considered, only $35 \%$ (638 million) are-adequately served.

These, of course, are average figures, and hide the tremendous disparity that exists even within the developing countries. The range of this disparity can be easily seen by considering the community water supply situation in the African continent. At the upper range are several countries where more than $90 \%$ of the urban opoulation are served by potable water. These are Botswana, Lesotho, Liberia (a11 100\%); Mauritius, Senegal (98\%); Gambia, Guinea, Ivory Coast, Kenya, Togo, Zambia (97\%); Benin, Egypt (94\%); Morocco and Tunisia $(91 \%)$. At the bottom end of the scale are the rural populations of several countries, where even $5 \%$ do not have access to safe water. These are Burundi, Gabon, Madagascar, Sierra Leone (1\% or less); Kenya (2\%); Gambia (3\%); Togo and Zaire $(5 \%)$, (Biswas, 1978). In addition, there are several other countries where data on rural sectors are not available, but they are virtually certain to be less than $5 \%$. These are Central African Republic, Ethiopia, Guinea and Lesotho (UN Economic and Social Counci1, 1976).

Universal availability of potable water will undoubtedly reduce health hazards like cholera, typhoid, infectious hepatitis, amobiasis, enterovirus: diarrhoeas and bacillary dysentery. It would further reduce human contacts with vectors of water-borne or water-based diseases like schistosomiasis, trypanosomiasis or guinea worm "(Dracunculus medinensis). Schistosomiasis will be discussed later. With regard to trypanosomiasis, Bradley (1974) has estimated that the Gambian sleeping sickness, Tryponosoma Gambiense, can be reduced by $80 \%$ by good water supply schemes. While this figure may be somewhat optimistic, there is no doubt that the provision of potable water will reduce the incidence of the dreaded sleeping sickness disease by reducing the exposure of human beings, especially women, to Tsetse flies during the water collection journey. Similarly, guinea worm infection, which currently affects some 48 million people, chiefly in India and West Africa (MUller, 1971), can also be reduced. Maximum infection occurs during dry periods, 
when people rely on ponds and other shallow sources. Infection rates of over $50 \%$ have been observed in India and Nigeria, and incidences of around 20 to $30 \%$ are commonly reported (Feacham, 1975). The health and economic costs to the communities can be substantially reduced by rational water resources development and management.

Water resources developments, however, do not only bring unmitigated benefits; they also are responsible for unanticipated social costs. Thus, one of the most serious impacts of irrigation developments in the tropical and semi-tropical regions is the secondary effect of spreading water-borne diseases, and the consequent suffering of millions of human beings and animals. Irrigation schemes have often enhanced or created favourable ecological environments for parasitic and water-borne diseases such as schistosomiasis, dengue, dengue hemorrhagic fever, liver fluke infections, bancroftian filariasis and malaria to flourish.

Schistosomiasis is currently endemic in over 70 countries, and affects over 200 million people. Prior to the development of the present extensive irrigation networks, and when agriculture depended primarily on seasonal rainfall, the relationship between snail host, schistosome parasite and human host was somewhat stabilized, and infection rates were low. Snail populations increased during the rainy season, when agriculture was possible, which provided the contact between man and parasites. During dry periods, however, there was a lull in infection. With the stabilization of water resource systems through the development of reservoirs and perennial irrigation schemes, the habitats for snails were vastly extended, and they also had a prolonged breeding phase which substantially increased their population.

The relationsip between water developments and increase in schistosomiasis has been conclusively demonstrated in several countries of the world. In Egypt; the replacement of simple primitive irrigation with perennial irrigation has caused a high incidence of both $S$. monson $i$ and $\dot{S}$. heamatobium. Where basin irrigation is still practised, the incidence is much less. Infection rates in four selected areas within three years of introduction of perennial irrigation, rose from 10 to $44 \%, 7$ to $50 \%, 11$ to $64 \%$ and 2 to $75 \%$. The 1 ife expectancy of males and females in heavily infected areas is estimated to be 27 and 25 years respectively. In Sudan, with the introduction of perennial irrigation to 900,000 acres under the Gezira Scheme, the incidence of blood fluke rose greatly. It also increased the incidence of flukes in cattle and sheep. In Kenya, the Lake Victoria is hyperendemic for schistomosiasis. 
S. mansoni infection in school children is up to $100 \%$ in areas associated with irrigation schemes. In Transvaal, South Africa, the 5 . monsoni infection rate in European farms was $68.5 \%$ compared with only $33.5 \%$ in the reserves, because the former had irrigation.

Constant availability of large quantities of water in reservoirs and canals is also conducive to the breeding of mosquitos, which act as intermediate host for diseases like malaria, bancroftian filariasis, yellow fever or arbovirus encephalitides. Currently, it is estimated that over 200 million people are infected with bancroftian filariasis (UNEP, 1977). Similarly, plant growths around water bodies provide a suitable habitat for the tsetse fly to transmit trypanosomiasis to human beings and domestic animals.

In contrast to the diseases discussed above, water developments tend to reduce the incidence of onchocerciasis. The intermediate host, simulum fly, tends to breed in fast-flowing water, and are often drowned by the construction of dams. Thus, the construction of the Volta Dam destroyed the breeding ground of simulum fly that existed upstream. However, adequate measures should be taken to ensure that new breeding places to not develop, especially in the fast-flowing waters near spillways.

HUMAN SUBSYSTEMS

The impacts of water developments on human subsystem could be direct or indirect, stemming from direct effects on physical and biological subsystems. These impacts can either be beneficial or adverse.

Provision of potable water to the rural or urban population is undoubtedly a major benefit of water developments. It immediately reduces the health hazards significantly, and further contributes to other major direct and indirect benefits. Thus, it is not surprising that the UN Conference on the Human Settlements considered the availability of potable water to all the population of the world a priority item, and recommended that such a development should be complete by 1990 (Biswas, M.R., 1978). The recently convened UN Water Conference further re-endorsed the importance of this step (Biswas, M.R., 1977).

A major beneficiary of the availability of potable water will be the women of the developing world, who currently spend considerable time in carrying water and collecting firewood. According to the Economic Commission for Africa of the United Nations, $90 \%$ of all water and fuel is collected by women; men only contribute to $10 \%$ of this task (UNECA, 1975). Thus, rational 
water resources development and management will reduce the water collection journey, mainly of women and children, who currently spend up to five hours every day collecting family water requirements. For example, if the water source is about $4 \frac{1}{2}$ miles away, a woman would spend at least 3 hours a day carrying water or $50 \%$ of her daily working time. If this time can be freed by providing water closer to their homes, it can be used for learning or productive work.

Time and inconvenience are not the only disadvantages of long water collection journeys for the women of the developing countries: it extols other costs as we11. It has been estimated that it takes up to $12 \%$ of daily calorie needs of most carriers in non-dry areas and in drier areas and in mountain regions, energy spent in collecting water and firewood may take up to $25 \%$ or more of the daily calories (Cleave, 1974). Women are not traditionally the most well-nourished members of the family: the most nutritious food being normally reserved for the men, the breadwinners of the family. Thus, elimination of water collection journeys for women, by providing potable water closer to home, has not only important implications in terms of reduced disease propagation (since contacts with disease vectors during long water collection journeys will be eliminated), but also in terms of nutrition, a fact often overlooked by planners and politicians.

Many of the major water development projects have also created other human problems, especially in terms of displacement of local inhabitants. Thus, the Volta Dam in Ghana has inundated an area of about 3,275 sq. miles, and the resulting lake has a shoreline of over 4,000 miles. As a result of the development, some 78,000 people and more than 170,000 domestic animals had to be evacuated from over 700 towns and villages of different sizes. Eventual1y, 52 new settlements were developed to house 69,149 people from 12,789 families (Jones and Rogers, 1976). It was a major problem since a large number of people coming from small villages (600 of the 700 original villages had less than 100 people, and only one had a population of over 4,000 ), and having different ethnic backgrounds, traditions, religions, social values and cultures, had to be resettled into only 52 locations. The complex emotional relationships between the different tribes and their lands were not properly understood. The development of a socially cohesive and integrated community, having a viable institution infrastructure became hard to achieve.

Similarly, the Kariba Dam on the River Zambesi (Zambesi and Rhodesia) displaced approximately 57,000 Tonga tribesmen, who had to pay a major price for this 
progress. Technology transfer at that level was a major problem, since many of the planners were from outside Africa. The resettlement program for the Tonga tribesmen left much to be desired; not only did they suffer great cultural shocks when being thrust into communities as different from their own, as theirs from Great Britain, but also it took two years to clear sufficient land to meet their subsistence needs. The government had to step in to avert famine and very serious hardships and, ironically, this goodintentioned step became one of the most destructive parts of the process. The food distribution centers also became transmission sites for the dreaded sleeping sickness disease.

Similar results from water development projects have, unfortunately, not been unique. Approximately 100,000 people had to be relocated for the Aswan High Dam without sufficient planning, and the World Food Program had to rush in famine relief for the Nubians. Other examples of lakes and populations displaced are the following: Lake Kainji in Nigeria--42,000; Keban Dam in Turkey--30,000; and Ubolratana Dam in Thailand--30,000 (UNEP, 1977).

Resettlement of population due to water development projects in many developing countries has not been a satisfactory experience. Inadequate planning, insufficient budget, incomplete execution of plans and little appreciation of the problems of technology transfer have all contributed to the failure of plans. The fact that much of the population to be resettled were rural and illiterate, and thus had very little political power, did not help either. The direct beneficiaries of the projects were often the educated elites, who are in power, whereas the direct social costs were mostly attributable to the rural poor.

CONCLUSIONS

There is no doubt that the primary effects of the vast majority of water development projects around the world have been beneficial. Equally, however, there is no doubt that many of these development projects have contributed to unanticipated adverse secondary effects, some of which could have been eliminated and others reduced in magnitude by appropriate planning processes. Thus, it is necessary that planning should move towards solutions that maximize the benefits occuring from water development, but it must do so without destroying the environmental basis for sustaining such production. Furthermore, any strategy to develop water resources on a sustained basis should take explicit account of the complementarity of environment and development, since 
their objectives are closely interrelated and mutually supportive.

The urgency and magnitude of developing new water resources projects to the end of the present century, to provide more water for municipal, industrial, agricultural, navigational, waste dilution and electricity generation purposes, should not be underestimated. It is, however, vitally important that planners and engineers should learn from past mistakes committed, and should not make similar mistakes all over again. The planning process should become more responsive to social and environmental problems, since long-term sustaining developments can only take place within the framework of appropriate environmental guidelines: otherwise, development will become a self-defeating process. It should be recognized that harmony can only come with integrated planning but discord is comparatively easy to produce. 
REFERENICES

1. Abl Atta, A., 1977, Country Speech of Egypt to the UN Water Conference, Mar del Plata, Argentina.

2. Biswas, Asit K., 1973, "Soico-Economic Considerations in thater Resources Planning", Water Resources Bulletin, Vol. 9, No.4, August 1973, pp. 746754.

3. Biswas, Asit K., 1978, "Some Policy Implications of Water Development", Journal of Hater Supply \& Hanagement, Vol. 2, No. 3.

4. Biswas, Asit K., and Biswas, Hargaret R., 1978, "Environmental Impacts of Increasing World's Food Production", Agriculture and Environment, Vol. 2, pp. 291-309.

5. Biswas, Asit $K_{.}$, and Biswas, Margaret $R_{2}, 1976$, "Hydro Power and the Environment", Water Power and Dam Construction, Vol. 28, No.5, pp.40-43.

6. Biswas, Margaret R., 1978, "Environment and Food Production", in Food, Climate and Man, Editors, M.R. Biswas and A.K. Biswas, John Wiley and Sons, New York.

7. Biswas, Asit K., and Robert W. Durie, 1971, "Sociological Aspects of Water Development", Water Resources Bulletin, Vol.7, No.6, pp.1137-1143.

8. Biswas, Margaret R., 1977, "United Nations Water Conferences: A Perspective", Journal of Water Suppiy and Management, Vol.1, No.3, pp. 255-272.

9. Biswas, Margaret R., 1978, "Habitat in Retrospect", International Journal for Environmental Studies, Vol. 11, pp.267-219.

10. Bradley, D.J., 1974, "Water Supplies: The Consequences of Change", in "Human Rights in Health, CIBA Foundation Symposium No. 23, Associated Scientific Publishers, Amsterdam, pp.81-98.

11. Cleave, J.H., "African Farmers: Labour Use in the Development of Smallhold Agriculture", Praeger Publishers, New York, p..166.

12. Feacham, R. 1975, "The Rational Allocation of Water Resources for the Domestic Needs of Rural Communities of Developing Countries", Proceedings, 2nd Congress, International liater Resources Association, New Delhi, 1975, pp.539-546.

13. Hafez, M. and Shenouda, W.K., 1977, "The Environmental Impacts of the Aswan High Dam", United llations Water Conference, E/CONF.70/TP17, Mar del Plata, $10 \mathrm{p}$.

14. Jones, J.0., and Rogers, P., Editors, 1976, "Human Ecology and Development of Settlements", Plenum Press, New York, pp.23-31.

15. Muller, R. 1971, "Dracunculus and Dracunculiasis", in Advances in Parasitology, Vol.9, Editor, B. Dawes, Acadenic Press, Naw York, pis. 73-15i. 
16. Malek, E.A., 1972, "Snail Ecology and Man-Made Habitats", in Schistosomiasis, Editor, H.J. Muller, Tulane University, New Orleans, Louisiana, pp.57-62.

17. Rothe, J.P., 1973, "Summary: Geophysics Report", in Man-ilade Lakes: Their Problems and Enviromental Effects, Editors, W.C. Ackermann, G.F. White and E.B. Worthington, Monograph No. 17, Aulerịcan Geophysical Union, Washington $D C, p p .441-454$.

18. UN Economic Commission for Africa, 1975, "Women of Africa Today and Tomorrow, UNECA, Addis Ababa, Ethiopia.

19. UN Economic and Social Council, 1976, "Problem of Water Resources Development in Africa", Document Ho. E/CN, 14/NRD/WR/1/Rev.2, Annex X, United Nations, New York.

20. Un Environment Programe, 1976, "Envionment and Development", Working Paper, UNEP/IG./4/3, UNEP, Nairobi, Kenya, pp.1-11.

21. UN Environment Programe, 1977, "Environmental Issues in River Basin Development", UN Water Conference, E/CON.70/A.26, United Nations, New Yor's, $12 \mathrm{p}$. 